\title{
Sonographic assessment of renal length in children: a reappraisal
}

\author{
J.M.Zerin', C.E.Blane ${ }^{2}$ \\ ${ }^{1}$ Department of Radiology, Riley Hospital for Children, Indiana University Medical Center, 702 Barnhill Drive, \\ Indianapolis, IN 46202-2920, USA \\ ${ }^{2}$ Department of Radiology, University of Michigan Hospitals, 1500 E. Medical Center Drive, Ann Arbor, MI 48109-0252, USA
}

Received: 20 September 1993/ Accepted: 2 December 1993

\begin{abstract}
Ultrasonography (US) has largely replaced the intravenous urogram as the first modality for the evaluation of the kidneys in children suspected of having urinary tract abnormalities. Because many renal disorders are associated with changes in the sizes of the kidneys, normative standards for assessing renal size have been developed. These standards rely upon comparison of the renal lengths or calculated volumes or both, with various assessments of overall body size, including body surface area, weight, height, and chronological age. We discuss some of the limitations of US in assessing renal size in children. Practical recommendations are offered for optimizing the measurement and interpretation of sonographic renal sizes in children.
\end{abstract}

Key words: Measurement, Renal length, Ultrasonography

Ultrasonography (US) is commonly used to evaluate the kidneys in children suspected of having urinary tract abnormalities and has largely replaced the intravenous urogram (IVU) in most clinical circumstances [1]. Many renal disorders are associated with changes in the size of the kidneys. For this reason, normative standards for assessing renal size have been developed [2-9] and are widely used in clinical practice. These standards rely upon comparison of the renal lengths or calculated volumes or both, with a variety of assessments of overall body size, including body surface area (BSA), weight, height, and chronological age. The published standards differ widely in the equipment and methods used for measuring and interpreting renal length. The selection of a particular set of standards for use in a specific clinical environment requires an understanding of the methodological differences between the various standards that are available, as well as the inherent limitations of US in assessing renal size. We discuss the role and limitations of US in evaluating renal size in children by addressing five questions:

1. Is there a reproducible and quantifiable relationship between renal size and the indices with which it is to be compared?

2. Are the methods for obtaining the measurements standardized and easily reproducible?

3. Is the population on which the standards are based comparable to the local patient population?

4. Are the methods for comparing the measurements in patients with the normative standards simple and accurate?

5. Does the comparison with the normative standards provide a result which can be logically applied in the management of patients?

\section{Is there a reproducible and quantifiable relationship between renal size and the indices with which it is being compared?}

\section{Renal size and body size}

Renal size correlates well with most commonly used parameters of overall body size, including height, weight, and BSA. Although renal size correlates best with BSA [3], the calculation of BSA is cumbersome and itself requires measurements of both height and weight. As a result, height and weight are usually used rather than BSA. Similarly, while renal volume theoretically correlates better with renal weight, renal length is directly measurable at US, whereas the calculation of volume requires multiple measurements [7, 10-11]. Most published standards for renal size at US rely on renal length rather than volume. 


\section{Renal size and chronological age}

Renal growth does not precisely parallel overall growth in body size [12-14]. The rate of renal growth is most rapid during the first 2 years of life and slows between 2 and 5 years, after which renal length increases by only 2-3 mm per year through adolescence [9]. Because body size and age are closely related throughout childhood, renal length correlates nearly as well with age as with height [3]. While weight correlates well with both height and chronological age in early childhood, there is greater variation in weight in adolescents and adults [15] and the normalization of renal length based on weight is probably less reliable.

\section{Right-left asymmetry in renal size}

The left kidney is usually (but not always) longer and larger in volume than the right $[3,5,12,16-18]$. This might explain some consistent right-left differences when comparing norms that assess right and left renal lengths separately [3] with others that not [8]. A single standard for evaluating both kidneys is simpler; however, it might also decrease sensitivity to reduced left renal length or increased right renal length or both. Because the difference in renal size between the two sides is small and inconstant, most standards do not provide different norms for the two kidneys.

\section{Differences in renal size between boys and girls}

Body size and proportions and the rate of general somatic growth and are strikingly different between boys and girls [15]. However, because there are no consistent differences in renal length (at US or IVU) between boys and girls $[5,16,18-20]$, none of the published standards evaluate renal length differently according to gender.

\section{Are the methods for obtaining the measurements standardized and easily reproducible?}

\section{Measurement of renal length}

It is important to adhere to the same method for measuring renal length as was used in defining the normative standards. Patient positioning (prone, supine or decubitus) and the trajectory of interrogation of the kidney are both important, but often difficult to standardize routinely. Changes in renal inclination and shape can affect the length of the longest measurable renal axis [21] and can be influenced by the position of the patient. As a result, coronal measurements of renal length made with the transducer in the mid- or anterior axillary line, with the patient supine or in a decubitus position, may not be comparable with posterior longitudinal measurements obtained with the patient prone.

Although it might be desirable to know how much the measurements can vary with the patient in different posi- tions, the position and transducer angle from which the longest renal axis can be obtained are routinely influenced by factors over which the examiner has little or no control. These include: interference by intestinal gas and overlying dressings, tubes, wounds, and scars; abnormalities in the position and axis of the kidneys [1, 21-22], and deformities of the patient's spine [23-24]. Gaseous intestinal distention in patients with neurogenic bowel (e. g., children with myelomeningocele) frequently interferes with visualization of the kidneys at US. Maneuvers designed to increase the visibility of the kidney (e.g., suspending respiration in deep inspiration, "pouching out the belly", or placing a bolster under the back) can similarly influence the measurements by altering renal inclination, shape, and position $[1,21]$. The state of hydration of the patient and the administration of diuretic medications or intravenous contrast material also can influence renal size [1,25-28].

The ultrasound equipment itself can influence the measurements. Transducers and software that permit improved resolution of the renal margins may limit the comparability of contemporary measurements with those reported a decade or more in the past $[3,8]$. Length measurements obtained with mechanical sector transducers can differ from those obtained with phased linear array probes [1]. Kidney that are longer than the width of the field of view cannot be accurately measured unless the scanning approach is changed or a standoff pad is used, both of which can affect the measurement [29]. Measurements made directly on the films with rulers or mechanical calipers [8] are generally less accurate than are those made using electronic calipers. Errors occurring when using mechanical calipers can result from both inaccurate caliper placement and from imprecise calibration of the distance scales printed on the films. The decision to use the maximum measurement of renal length as opposed to the average of several measurements can also make a difference [30].

Intraobserver and interobserver reproducibility of the renal length measurements is an important problem which is not only related to variations in operator competence. Measurements also frequently differ widely between equally experienced practitioners examining the same patient using the same equipment within several minutes of each other [30]. Although variations in caliper placement can be a factor, differences in scanning technique, angle of interrogation of the kidneys, and changes within the patient that influence the visibility of the kidney, are all important. Limitations in the reproducibility of measurements of renal length can result in considerable confusion by giving the impression that the kidneys are shrinking or enlarging excessively from one examination to the next.

Since the purpose of assessing renal size with US is to estimate the volume of functioning renal parenchyma, measurements of the length or volume, or both, of hydronephrotic or cystic kidneys can be misleading. For example, in a child with hydronephrosis due to uretero-pelvic junction obstruction, improvement in the hydronephrosis following pyeloplasty can be accompanied by a reduction in the overall renal size. This change in renal size 
does not accurately indicate a corresponding change in either the volume or functional status of the renal parenchyma, which may be improved following relief of the obstruction.

\section{Measurement of height and age}

The patient's height must be measured carefully, using the proper equipment, to ensure accuracy. Height is measured in a different way in children under 3 years (i.e., length is measured) from that used in children older than 3 years (i.e., stature is measured) [15]. Parental estimates of their children's heights are often inaccurate in our experience, and are usually given in inches (in the United States), requiring conversion to metric equivalents. Unfortunately, few of the published standards for correlating renal length with height describe the method used for measuring height.

Measurements of height can be meaningless when made for comparitive purposes in children with kyphoscolosis and other disorders of the spine, pelvis, and lower extremities [16]. In addition, both visceral and skeletal growth can be slowed in children with renal insufficiency, potentially reducing the accuracy of the comparison of height and renal length in children with diminished renal function. Age, on the other hand, can be obtained quickly and with great accuracy by asking the patient (or the patient's parent) or by subtracting the date of birth from the date of the examination.

\section{Is the population on which the standards are based comparable to the local patient population?}

Dinkel et al. [3] studied children from Freiberg, Germany. Rosenbaum et al. [8] studied children from Boston, Mass. It is not known whether their standards are applicable to children elsewhere. Simpson et al. [31] found that the norms published by Eklof and Ringertz [32] (based on a Swedish population) for renal length at urography were not applicable to a British population. This problem is not unique to renal length. Racial, ethnic, socioeconomic, geographic, nutritional, and historical differences between the local patient population and the population on which the norms were based can affect the appropriateness of the comparison of all somatometric data [33].

When we reviewed the measurements of renal length in 130 consecutive patients studied in Ann Arbor the $z$-scores (i.e., the units of standard deviation above or below the mean) for renal length based on our patients' heights (using Dinkel et al. [3]) were consistently greater (i.e., less negative or more positive) than those based on age (using Rosenbaum et al. [8]). In fact, the $z$-scores for renal length based on height exceeded the $z$-scores based on age in almost all the children, regardless of whether or not their heights were normal for age. This suggests that there could be systematic differences in height or renal length, or both, between our patients and the populations on which the standards were based.

\section{Are the methods for comparing the measurements in patients with the normative standards simple and accurate?}

The method that is used for applying the standards in practice will affect the result. The importance of such variations depends upon the method that is used and the degree of precision that is required by the referring physicians.

Calculation of $z$-scores or percentiles based on regression equations provides a simple mathematical method that works well for comparing renal length and height since the relationship is approximately linear. Because the rate of renal growth is not the same at all ages, linear regression equations are less satisfactory for comparing renal length with age. Accuracy could be improved by providing multiple equations for different age groups [5], although this complicates the analysis.

These problems can be overcome by using tables of mean renal lengths and the associated standard deviations in children of different ages. Since patients are rarely examined on their birthdays, interpolation of the means and standard deviations may be slightly more accurate than using the last birthday or rounded age, but again is more complicated.

Plotting the measured length or volume on a graph obviates the need for any calculations. Visual inspection of a growth chart after plotting the results of multiple examinations can give an excellent semi-quantitative analysis of the progress of renal growth $[12,34]$ (Fig. 1). Truly quantitative comparison of lengths at multiple examinations still requires calculation of $z$-scores or percentiles by one of the above methods. Computerization of the calculation or plotting procedures, or both, would improve precision and reduce errors in calculation (although not errors in measurement or data recording). To our knowledge, no such programs are available.

\section{Does the comparison with the normative standards provide a results which can be logically applied in the management of patients?}

By convention, measurements of renal length are arbitrarily judged to be within the "normal range" if they are within 2 standard deviations of the normative population's mean, or are between the 5th and 95th percentiles of the measurements made in a normally distributed normative population [1]. Although this standard does provide a simple method for differentiating "normal" from "abnormal", approximately $10 \%$ of children with normal kidneys will have renal lengths that fall outside this "normal" range [35].

Conversely, because renal length varies so widely among normal children, an undetermined percentage of kidneys will have lengths that are abnormal because of disease, but not so severely abnormal that they fall outside the normal range. For example, using the standards of Rosenbaum et al. [8], a right kidney measuring $7 \mathrm{~cm}$ in length could be normal from under 6 months to nearly 7 years of age. Using the standards of Dinkel et al. [3] a 


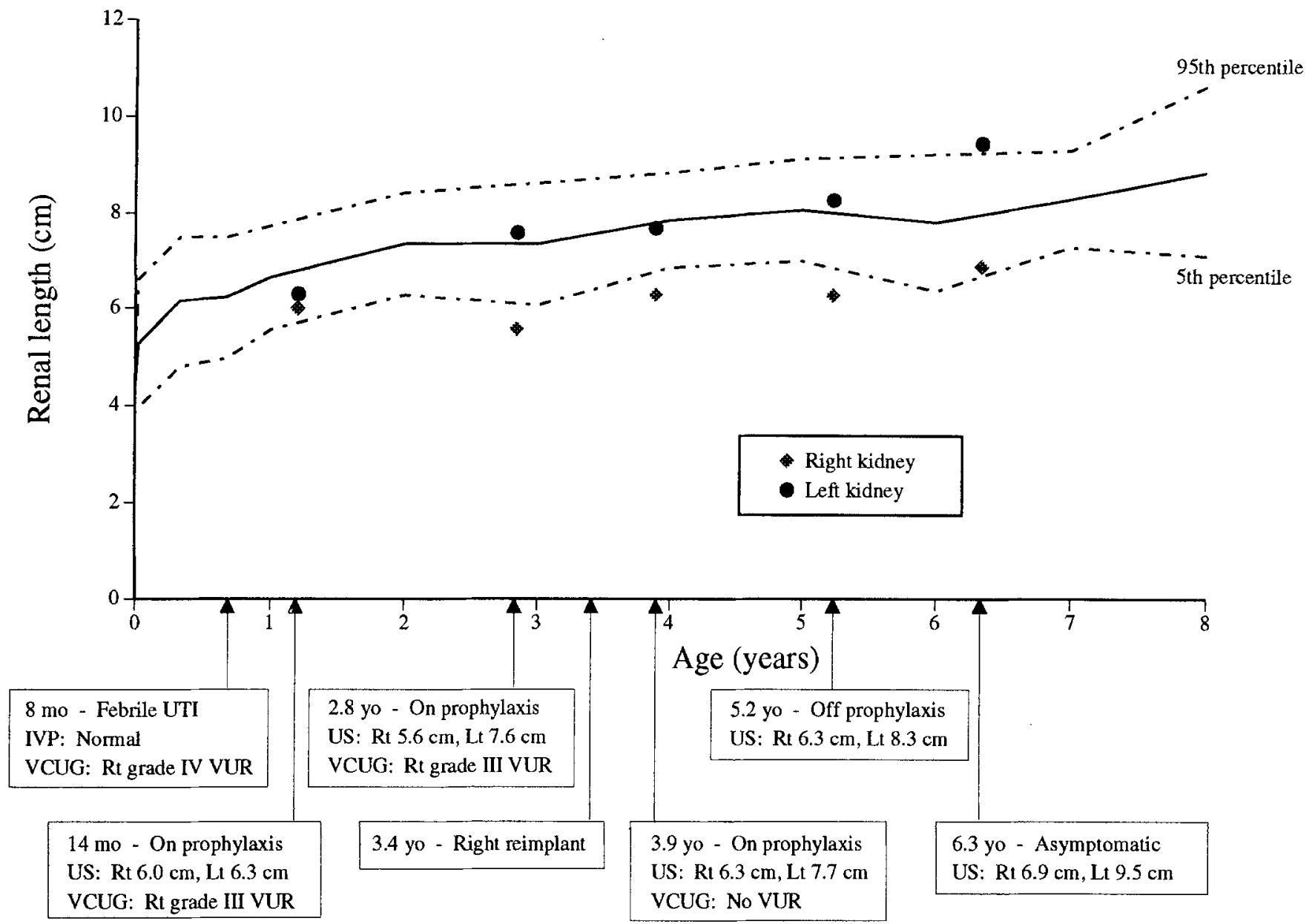

Fig.1. Annotated renal growth chart in a boy with reflux nephropathy consequent to right reflux and acute pyelonephritis at 8 months of age. Renal lengths at five consecutive examinations are plotted against normative standards for renal length based on age [8]. Initially, both IVP and renal US were normal. However, despite antibiotic prophylaxis, reimplantation, and the absence of further infection, the right kidney grew little while the left kidney hypertrophied, resulting in increasing asymmetry of the renal lengths over time. $I V P$, intravenous pyelography; $L t$, left; $m o$, months of age; $R t$, right; $U S$, ultrasonography; $U T I$, urinary tract infection; $V C U G$, voiding cysto-urethrography; $V U R$, vesico-ureteral reflux; yo, years of age

right kidney measuring $7 \mathrm{~cm}$ could be normal in a child having a height from $79 \mathrm{~cm}$ (95th percentile for height at 9 months [15]) to $127 \mathrm{~cm}$ (5th percentile for height at 10 years [15]). Although using a narrower range would theoretically improve sensitivity, it would also result in a larger number of falsely "abnormal" measurements [35].

Documentation that the renal lengths are "normal" at the time of a single examination does not guarantee that the kidneys have been growing normally or that they will continue to do so in the future. The potential for growth can only be assessed by comparing measurements that have been obtained on sequential studies (i. e., a renal growth chart) [17,34] (Fig. 1). This has important implications for protocols that call for a single US examination and follow-up imaging only if the screening study is abnormal. Because the "normal" range for renal length is as wide as it is, a second examination may be necessary after an appropriate interval to ensure that the kidneys are growing.

In children with urinary tract infection, the timing of the screening US is important to its interpretation. Renal injury, consequent to vesicoureteral reflux and pyelonephritis, is not usually apparent at US performed immediately following the infection. Cortical scarring and atrophy develop over months, and deceleration in the rate of renal growth may become apparent only after many months or even years have passed [36] (Fig. 1). For example, a $7 \mathrm{~cm}$ kidney in an 18 -month-old child with reflux and acute pyelonephritis, would remain within 2 standard deviations of the mean for more than 6 years [8] even if it had stopped growing entirely at the time of the original pyelonephritis.

Conversely, if a child is examined during an episode of acute pyelonephritis, renal edema secondary to the infection can give rise to a greater measurement of renal length (often without identifiable focal changes in parenchymal echogenicity). In this circumstance, the US examination may provide inaccurately "normal"-seeming measurements, since the length of a small kidney can temporarily fall within the normal range when the kidney is enlarged from edema. Thus the effect of previous retardation in the rate of renal growth is masked. If the child is not re-examined after the acute infection has resolved, the presence of significant impairment in renal 
growth can go undetected. On the other hand, if the child is re-examined, the renal length can appear to decrease in an exaggerated fashion, a phenomenon often mistakenly ascribed to "interobserver variability".

Asymmetry in the lengths or volumes of the kidneys can be an important clue that one or both kidneys are abnormal even when measurements of both are within the "normal range" (Fig.1). Since duplex kidneys are frequently longer than their simplex counterparts, such asymmetry can be due to the presence of a duplex kidney on one side in some cases [1]. However, this may be a less common cause of asymmetry than is often claimed, since duplication of the upper urinary tract is bilateral in up to $39 \%$ of cases [37] and asymmetry is an inconstant finding even in cases of unilateral duplication. Although the left kidney is usually somewhat longer and larger in volume than the right kidney $[3,5,12$, 16-18], the reverse is true in a minority of normal individuals. The degree of asymmetry that is acceptable as normal is probably less when the right kidney is the larger of the two. The threshold for distinguishing acceptable from excessive asymmetry in renal length at US has not been established in children and probably changes with age (and renal size). Increasing discrepancy in the renal lengths over time should always be a cause for concern.

\section{Discussion}

Despite its limitations, sonographic assessment of renal length is extremely useful in the evaluation of children with urologic signs or symptoms. Both height and age correlate well with renal length. Although height may theoretically be more reliable, age is simpler to assess.

Limitations in intraobserver and interobserver reproducibility of measurements of renal length is an important problem. Differences in scanning technique and cursor placement and dynamic changes within the patient affecting the visibility of the kidneys affect the reproducibility of measurements of renal length using US.

The extent to which changes in patient positioning and the trajectory of interrogation of the kidneys during scanning influence the measurement of renal length is not completely understood. However, when comparing measurements of renal length with published standards, the scanning method described in the standards should be used.

Plotting serial renal length measurements on a growth chart can be useful in detecting important changes in the rate of renal growth. Annotation of the growth chart with related clinical information (e.g., dates of infection, surgery, etc.) enhance the usefulness of the chart as a visual diagnostic aid (Fig. 1). Some children having screening US of the kidneys (e.g., children with urinary infection) may require follow-up examinations to document satisfactory renal growth, even when the initial findings are "normal". Conversely, documentation that the kidneys are growing steadily parallel to a percentile line can be reassuring in a child with seemingly abnormally small kidneys.
It is desirable to closely evaluate children with asymmetric renal lengths (exceeding 5-10 mm), and to maintain a high index of suspicion for an underlying problem in such children, even when measurements for each individual kidney are within the "normal" range. Further research is needed to improve our understanding of variations in the rate of renal growth throughout childhood and the amount of asymmetry in renal lengths that is normally encountered.

\section{References}

1. Teele RL, Share JS (1991) Ultrasonography of infants and children. Saunders, Philadelphia

2. Blane CE, Bookstein FL, DiPietro MA, Kelsch RC (1985) Sonographic standards for normal infant kidney length. AJR 145: 1289-1291

3. Dinkel E, Ertel M, Dittrich M, Peters H, Berres M, Schulte-Wissermann $H$ (1985) Kidney size in childhood: sonographical growth charts for kidney length and volume. Pediatr Radiol 15: $38-43$

4. Erwin BC, Carrol BA, Muller H (1985) Sonographic assessment of neonatal renal parameters. J Ultrasound Med 4:217-220

5. Han BK, Babcock DS (1985) Sonographic measurement and appearance of normal kidneys in children. AJR 145: 611-616

6. Haugstvedt S, Lundberg J (1980) Kidney size in normal children measured by sonography. Scand J Urol Nephrol 14: 251-255

7. Holloway H, Jones TB, Robinson AE, Harpen MD, Wiseman HJ (1983) Sonographic determination of renal volumes in normal neonates. Pediatr Radiol 13: 212-214

8. Rosenbaum DM, Korngold E, Teele RL (1984) Sonographic assessment of renal length in normal children. AJR 142: 467469

9. Schlesinger AE, Hedlund GL, Pierson WP, Null DM (1987) Normal standards for kidney length in premature infants: determination with US. Radiology 164: 127-129

10. Jones TB, Riddick LR, Harpen MD, Dubuisson RL, Samuels D (1983) Ultrasonographic determination of renal mass and renal volume. J Ultrasound Med 2: 151-154

11. Moskowitz PS, Carroll BA, McCoy JM (1980) Ultrasonic renal volumetry in children. Radiology 134: 61-64

12. Effman EL, Ablow RC, Siegel NJ (1977) Renal growth. Radiol Clin N Am 15: 3-17

13. Dicker SE, Morris C (1974) Renal control of kidney growth. J Physiol (Lond) 241: 20-21

14. Nash MA, Edelmann CM Jr (1973) The developing kidney. Nephron 11: 71-90

15. Hamill PV, Drizd TA, Johnson CL, Reed RB, Roche AF, Moore WM (1979) Physical growth: National Center for Health Statistics percentiles. Am J Clin Nutr 32: 607-629

16. Gross GW, Thornburg AJ, Bellinger MF (1986) Normal renal growth in children with myelodysplasia. AJR 146: 615-617

17. Friedenberg MJ, Walz BJ, McAlister WH, Locksmith JP, Gallagher TL (1965) Roentgen size of normal kidneys. Computer analysis of 1286 cases. Radiology 84: 1022-1030

18. Currarino G, Williams B, Dana K (1984) Kidney length correlated with age: normal values in children. Radiology 150: 703704

19. Hodson CJ, Drewe JA, Karn MN, King A (1962) Renal size in normal children: a radiographic study during life. Arch Dis Child 37: 616-622

20. Jorulf H, Nordmark J, Jonasson A (1978) Kidney size in infants and children assessed by area measurement. Acta Radiol Diagn 19: $154-162$

21. Farrant $P$, Meire HB (1978) Ultrasonic measurement of renal inclination; its importance in measurement of renal length. $\mathrm{Br} \mathrm{J}$ Radiol 51: 628-630 
22. Riggs W Jr, Hagood JH, Andrews AE (1970) Anatomic changes in the normal urinary tract between supine and prone urograms. Radiology 94: 107-113

23. Fernbach SK, Davis TM (1986) The abnormal renal axis in children with spina bifida and gibbus deformity - the pseudohorseshoe kidney. J Urol 136: 1258-1260

24. Gross GW, Boal DK (1988) Sonographic assessment of normal renal size in children with myelodysplasia. J Urol 140: 784-786

25. Arkless R (1969) The normal kidney's reaction to intravenous pyelography. AJR 107: 746-749

26. Dorph S, Sovak M, Talner LB, Rosen L (1977) Why does kidney size change during I. V. urography? Invest Radiol 12: 246-250

27. Hodson CJ (1961) Physiological changes in size of the human kidney. Clin Radiol 12:91-94

28. Wolpert SM (1965) Variation in kidney length during intravenous pyelogram. Br J Radiol 38: 100-103

29. Carpenter BM, Ritenour MN, Day DL (1991) Inaccurate sonographic renal length measurement with a standoff pad. Presented at the 77th Annual Assembly of the Radiological Society of North America, Chicago, December
30. Schlesinger AE, Hernandez RJ, Zerin JM, Marks TI, Kelsch RC (1991) Interobserver and intraobserver variations in sonographic renal length measurements in children. AJR 156: 1029 1032

31. Simpson W, Cranage JD; Furness JA (1981) Kidney size compared with vertebral height. Acta Radiol Diagn 22: 321-324

32. Eklöf O, Ringertz H (1976) Kidney Size in Children. Acta Radiol [Diagn] (Stockh) 17: 617-625

33. Zerin JM, Hernandez RJ (1991) Approach to skeletal maturation. Hand Clin 7: 53-62

34. Lebowitz RL, Hopkins T, Colodny AH (1975) Measuring the kidneys - practical applications using a growth and hypertrophy chart. Pediatr Radiol 4: 37-42

35. Remington RD, Schork MA (1985) Statistics with applications to the biological and health sciences. Prentice Hall, Englewood Cliffs, New Jersey, pp. 23-34

36. Ginalski JM, Michaud A, Genton N (1985) Renal growth retardation in children sign suggestive of vesicoureteral reflux? AJR 145: 617-619

37. Gonzales ET Jr (1992) Anomalies of the renal pelvis and ureter. In: Kelalis PP, King LR, Belman AB (eds) Clinical pediatric urology, 3rd edn. Saunders, Philadelphia, pp 530-532

\section{Literature in pediatric radiology}

\section{Medical and Pediatric Oncology (New York)}

Bone and Gallium scintigraphy in children with rhabdomyosarcoma: a 10-year review. Cogswell, A. et al. (Howman-Giles, R., Dept. of Nucl. Med., The Children's Hosp., Bridge Rd., Camperdown, Sidney, N.S.W., Australia, 2050) 22: 15 (1994)

Wilms' tumor involving the inferior vena cava: preoperative evaluation and management. Federici, S. et al. (Clinica Chirurg. Ped., Univ., Policlinico Santa Orsola, Via Massarenti 11, I-40138 Bologna, Italy) 22: 39 (1994)

Malignant oligodendroglioma arising after radiation therapy for lymphoma. Corn, B. et al. (DÁngio, G.J., Dept. of Radiation Oncol., Hosp. of the Univ., 3400 Spruce St., Philadelphia, PA 19104, USA) 22: 45 (1994)

Right atrial thrombosis associated with central venous catheters in children with cancer. Wacker, P. et al. (Ped. Hematol/Oncol. Unit, Hôpital des Enfants, 30 Blvd. de la Cluse, CH-1205 Geneva, Switzerland) 22: 53 (1994)

Thymic cyst appearing after treatment of mediastinal non-Hodgkin lymphoma. Borgna-Pignatti, C. et al. (Dept. of Ped., Clinica Ped., Univ., Policlinico Borgo Roma, I-37134 Verona, Italy) 22: 70 (1994)

Pediatric Clinics of North America (Philadelphia) Hypoxic-ischemic brain damage in the term infant. Lessons from the laboratory. Pasternak, J.F. (Dept. of Ped. and Neurol., Northwestern Univ. Med. School, Chicago, IL, USA) 40: 1061 (1993)

Tuberculosis in infancy in the 1990s. Rosenfeld, E. A. et al. (Div. of Infectious Diseases, Children's Memorial Hosp., Chicago, IL, USA) 40: 1087 (1993)
Radiology (Easton PA)

Childhood adrenoleukodystrophy: assessment with proton MR spectroscopy. Tzika, A.A. et al. (Dept. of Rad., Children's Hosp. Med. Center, Cincinnati, OH, USA) 189:467 (1993)

Brachial plexopathy in infants after traumatic delivery: evaluation with MR imaging. Miller, S. F. et al. (Glasier, C.M., Dept. of Rad., Univ. for Med. Sciences and Children's Hosp., 800 Marshall St., Little Rock, AR 72202, USA) 189: 481 (1993)

\section{Surgery (St. Louis)}

Congenital hemangiopericytoma: an unusual vascular neoplasm of infancy. Bailey, P.V. et al. (Weber, T.R., Div. of Ped. Surg., Cardinal Glennon Children's Hosp., 1465 S. Grand Blvd., St. Louis, MO 63104, USA) 114:936 (1993)

\section{Archives of Disease in Childhood (London)}

Bronchocutaneous fistula associated with mechanical ventilation. Baildam, E.M. et al. (Booth Hall, Children's Hosp., Blackley, Manchester, M9 2AA, UK) 69:525 (1993)

\section{British Journal of Radiology (London)}

Case report: child abuse - necklace calcification - a sign of strangulation. Carty, H. (RLCNHS Trust, Alderhey, Eaton Rd., Liverpool L12 2AP, UK) 66: 1186 (1993)

Case report: computed tomography of generalized lymphangiomatosis and chylothorax. Higgins, J. N.P. et al. (Royal Free Hosp. Pond St., Hampstead, London NW3 20G, UK) 66: 1189 (1993)
Continued from p. 100

Clinical Radiology (Edinburgh)

Signal intensity patterns in intraspinal dermoids and epidermoids on MR imaging. Gupta, S. et al. (Dept. of Rad., Sanjay Gandhi Postgraduate Inst. of Med. Sciences, PB No.375, Raibareli Rd., Lucknow 226001, India) 48: 405 (1993)

Archives Françaises de Pédiatrie (Paris)

Late periventricular leukomalacia in a premature infant. [In French] Debillon, T. et al. (Serv. de Péd. et Réanimation néonatales, Hôpital Antoine-Béclère, 157, rue de la Porte-de-Trivaux, F-92141 Clamart, France) 50: 671 (1993)

Un cas de kyste anévrysmal du péroné par un traumatisme. Durup de Baleine, D. et al. (Serv, de Péd.-Néonatol., CHG, F-55107 Verdun, France) 50: 701 (1993)

Un cas de pancréatite aiguë à l'asparaginase (cas radiologique du mois). Chapot, $\mathrm{R}$. et al. (Ducou Le Pointe, H., Serv. de Rad., Hôpital d'Enfants Armand-Trousseau, 26, av. du Dr.-Arnold-Netter, F-75571 Paris Cedex 12, France) 50: 705 (1993)

\section{Journal de Radiologie (Paris)}

Smith-Lemli-Opitz syndrome, type II. The role of imaging. [In French] Herman, T.E. (Mallinckrodt Inst. of Rad., Washington Univ. School of Med., 510 S. Kingshighway Blvd., St. Louis, MO 63110, USA) 74:593 (1993) 